\title{
Short communication: Cheese supplemented with Thymus algeriensis oil, a potential natural food preservative
}

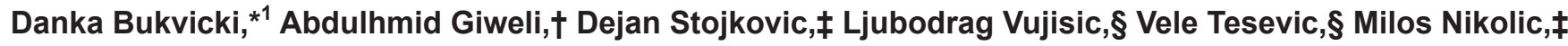 \\ Marina Sokovic, $\ddagger$ and Petar D. Marin* \\ *University of Belgrade - Faculty of Biology, Institute of Botany and Botanical Garden "Jevremovac," 11000 Belgrade, Serbia \\ †Department of Botany, Faculty of Science, University of Al-Gabel Al-Garbe, Zintan, Libya \\ łUniversity of Belgrade - Institute for Biological Research "Sinisa Stankovic," Bulevar Despota Stefana 142, 11000 Belgrade, Serbia \\ §University of Belgrade - Faculty of Chemistry, Studentski trg 12-16, 11000 Belgrade, Serbia
}

\section{ABSTRACT}

The essential oil of Thymus algeriensis was analyzed as a potential preservative in soft cheese. We developed a novel method to test the preserving properties of essential oil in soft cheese. Contamination incidence of Penicillium aurantiogriseum was absent after $30 \mathrm{~d}$ of storage at $4^{\circ} \mathrm{C}$ with $25 \mu \mathrm{L}$ of essential oil added. The antimicrobial activity was tested against 8 bacteria and 8 fungi. Thymus algeriensis oil showed inhibitory activity against tested bacteria at 0.03 to $0.09 \mathrm{mg} /$ $\mathrm{mL}$, and bactericidal activity was achieved at 0.05 to $0.15 \mathrm{mg} / \mathrm{mL}$. For antifungal activity, minimum inhibitory concentrations ranged between 0.01 and $0.04 \mathrm{mg} /$ $\mathrm{mL}$ and minimum fungicidal concentrations between 0.01 and $0.04 \mathrm{mg} / \mathrm{mL}$. Furthermore, the oil was also screened for antiradical activity using the 1,1-diphenyl2-picrylhydrazyl assay. The results showed that the oil was active and achieved half-maximal inhibitory activity at $0.132 \mathrm{mg} / \mathrm{mL}$. We used gas chromatography, gas chromatography-mass spectrometry, and nuclear magnetic resonance spectrometry to investigate the volatile compounds from the oil. Carvacrol was identified as the main compound in the oil, represented by $80.9 \%$ of the total constituents, followed by $p$-cymene $(7.7 \%)$.

Key words: Thymus algeriensis, essential oil, carvacrol, antimicrobial, cheese preservation

\section{Short Communication}

Dairy products can be easily contaminated by pathogens or food spoilage microorganisms, which can produce unwanted appearance, decrease commercial value, and, most importantly, compromise the safety

Received August 19, 2017.

Accepted December 12, 2017.

${ }^{1}$ Corresponding author: dankabukvicki@gmail.com of products. Molds on the surface of cheese cause undesirable flavors and many quality problems. The most frequently isolated mold genus from cheese is Penicillium spp., which may produce mycotoxins such as ochratoxin A and citrinin (Torkar and Vengust, 2008). Some studies have shown that natural compounds may protect cheese from food contaminant microorganisms (Smith-Palmer et al., 2001; Lucera et al., 2012); Gammariello et al. (2010) reported that chitosan and lemon extract improve shelf life of Mediterranean fresh cheese.

Plant products and their derived compounds are of growing interest due to the wide range of bioactivities that make them useful as natural additives in different types of food. For centuries, they have been used for treatment of infections and diseases worldwide (Rios et al., 1988; Skrinjar and Nemet, 2009; Gottardi et al., 2016). In recent years, utilization of plant products [e.g., essential oils (EO), extracts, and their secondary metabolites] has gained considerable interest for the food industry as an alternative to synthetic antimicrobials or additives (Bukvicki et al., 2014a,b, 2015; Tyagi et al., 2014).

The majority of the thyme species are widely used as medicinal herbs (Oussalah et al., 2007) and known to have biological activities, such as antispasmodic (Babaei et al., 2008), sedative (Fachini-Queiroz et al., 2012), antioxidant (Lee et al., 2005), and antimicrobial (Oussalah et al., 2007; Hazzit et al., 2009) activities. The focus of our study was potential application of Thymus algeriensis EO in soft cheese, and we aimed to investigate the effect of the oil as preservative in this dairy product. For such purposes, we developed a novel method to test antimicrobial food-preserving properties of substances in soft cheese. Furthermore, chemical characterization of the EO and its antiradical attributes and antimicrobial activities were investigated.

Thyme plants were collected from Gharyan city (Al Gabel Al-Garbe, Libya) in April 2012. The plant was identified by A. Giweli and then confirmed by P. D. Marin. One hundred grams of air-dried aerial parts of 
plant samples, with woody parts removed, were submitted to hydrodistillation (Bukvicki et al., 2014a).

The volatile composition of the $T$. algeriensis EO was determined according to a previously published procedure (Bukvicki et al., 2016). The components were identified by comparison of mass spectra with reference from commercial libraries (Wiley 7, NIST 11, and Adams 4; McLafferty, 2005; Adams, 2007; NIST, 2011). Structural determination of each component was confirmed by comparison of retention indices $(\mathbf{R I})$ obtained by the standard method (Vandendool and Kratz, 1963) with the Adams 4 RI library. Quantitative ${ }^{1} \mathrm{H}$ nuclear magnetic resonance (NMR) analysis of the T. algeriensis $\mathrm{EO}$ was performed by using a Bruker Avance III 500 NMR spectrometer $(500 \mathrm{MHz}$, Bruker, Rheinstetten, Germany) in deuterated chloroform $\left(\mathrm{CDCl}_{3}\right)$, with tetramethylsilane as a reference and 2,6-bis(1,1-dimethylethyl)-4-methylphenol (butylated hydroxytoluene, BHT) as an internal standard. Essential oil (5.260 mg) and BHT (5.050 mg) were dissolved in $500 \mu \mathrm{L}$ of $\mathrm{CDCl}_{3}$ in a 5 -mm NMR tube. Proton NMR spectra were run with a standard pulse sequence with 16 scans, and with 3 different relaxation delays (d1) times of 1,4 , and $10 \mathrm{~s}$. The BHT was selected because its ${ }^{1} \mathrm{H}$ NMR signals (aromatic proton) are clearly distinguishable from those of EO components (Figure 1). Peak area of characteristic protons used for quantitative calculation was manually integrated. Signal of 1 proton of carvacrol [chemical shift $(\boldsymbol{\delta}) 7.03$ doublet, coupling constant $(J)=7.7 \mathrm{~Hz}], 2$ signals of 4 protons of $p$-cymene ( $\delta 7.07-7.15$ multiplets), and signal of 2 protons of $\mathrm{BHT}$ ( $\delta 6.98$ singlet) were used for relative percentage calculation, based on the equation

$$
P x(\%)=\frac{M x}{M s} \times \frac{m_{s}}{m_{E 0}} \times \frac{I x}{I s} \times \frac{n_{s}}{n_{x}} \times 100,
$$

where $M x$ and $M s$ are the molar masses of the analyte and the internal standard (BHT); $\mathrm{m}_{\mathrm{E} 0}$ and $m_{S}$ are the weighed mass of the essential oil of T. algeriensis and BHT; Ix and $I s$ are the peak areas of the analyte and $\mathrm{BHT}$; and $n_{x}$ and $n_{s}$ are the numbers of the protons generating the corresponding peak of the analyte and BHT, respectively. The 1,1-diphenyl-2-picrylhydrazyl (DPPH) assay was done according to a previously published procedure (Dzamić et al., 2015), as were the assays for antibacterial and antifungal activity (Bukvicki et al., 2016).

Soft cheese used in our experiment was obtained from a market located in Belgrade (Serbia). Soft cheese (domaći mladi sir, without preservatives; Président/ Group Lactalis, Laval, France), with nutritional values of $5.5 \%$ milk fat, $4 \%$ carbohydrates, and $12.5 \%$ protein, was stored at $4^{\circ} \mathrm{C}$ for until further use. Cheese was sliced into equal cuboid shapes, with an approximate weight per slice of $20 \mathrm{~g}$, and placed in sterile petri dishes. For the in situ antifungal assay, we developed a convenient assay for all investigations. Slices of soft cheese were pierced ( $5 \mathrm{~mm}$ deep and $5 \mathrm{~mm}$ wide), creating 3 wells per slice. Each treatment had 2 replicates with 5 slices of cheese per replicate. Essential oil of T. algeriensis was dissolved in different concentrations of sterile $0.2 \%$ Tween 80 (vol/vol). Essential oils were applied at 1, 5, $10,15,20$, and $25 \mu \mathrm{L}$, and then $25 \mu \mathrm{L}$ of EO emulsion was placed into each well made in cheese. After $1 \mathrm{~h}$, $25 \mu \mathrm{L}$ of a conidial suspension $\left(2 \times 10^{4}\right.$ conidia $\left./ \mathrm{mL}\right)$ of Penicillium aurantiogriseum was added to each well in sliced cheese. As a positive control of fungal growth, $P$. aurantiogriseum was inoculated on cheese without EO. The treated slices of cheese were stored at $4^{\circ} \mathrm{C}$ for $30 \mathrm{~d}$, respectively. After storage, the number of wells that showed contamination symptoms (fungal growth) was recorded, and contamination incidence (\%) was calculated as

Contamination incidence $=$ (number of infected wells $/$ total wells per replicate) $\times 100$.

To evaluate possible changes in color, texture, and flavor, cheese was sprayed with EO at levels of 1,5 , and $15 \mu \mathrm{L}$ per surface of sliced cheese [diluted EO at 1,5 , and $15 \mu \mathrm{L}$ in $100 \mu \mathrm{L}$ of $0.2 \%$ Tween 80 (vol/ vol) in water], with 1 control sample not sprayed with EO. Test was made in initial shelf-life, third day after production. Results were expressed as average grades given by 20 panelists (Bukvicki et al., 2014a).

Based on GC and GC-MS analysis, 21 compounds were identified, representing $99.7 \%$ of the total oil. Carvacrol was the main compound in the oil (80.9\% of total oil), followed by $p$-cymene $(7.7 \%)$. In addition, 2 components of analyzed EO were identified and quantified by ${ }^{1} \mathrm{H}$ NMR (Figure 1). Relative mass percentage of carvacrol was 72.8 and $p$-cymene 7.6 ; moreover, substitutional isomers of cymene $\left(o-, m_{-}, p-\right)$ have similar mass spectra, and RI, GC, and GC-MS analysis could be time consuming. Otherwise, differences among proton NMR spectra of isomers of cymene provide clear identification. The NMR analysis could be the method for quality control of chemical composition of $\mathrm{EO}$ with few dominant compounds.

Thymus algeriensis EO, its main component carvacrol, and butylated hydroxyl anisole had good antiradical potential as investigated by the DPPH assay (results in Figure 2). Our investigations showed that $T$. algeriensis EO exhibited notable free radical scavenging activity, with half-maximal inhibitory concentra- 
tion $\left(\mathrm{IC}_{50}\right)$ of $0.132 \mathrm{mg} / \mathrm{mL}$, although it was weaker than carvacrol alone $\left(\mathrm{IC}_{50}=0.105 \mathrm{mg} / \mathrm{mL}\right)$. The good antiradical potential of the oil could be attributed to carvacrol, as such a relation was previously shown for oxygenated monoterpenes by Hazzit et al. (2009).

The results of the antimicrobial activity tested by microdilution method are summarized in Table 1. The EO of T. algeriensis exhibited significant antimicrobial activity against all strains tested. For antibacterial activity, the inhibition values ranged from an MIC of 0.03 to $0.09 \mathrm{mg} / \mathrm{mL}$ and minimum bacterial concentration of 0.05 to $0.18 \mathrm{mg} / \mathrm{mL}$. It can be seen that the oil showed activity better than the positive control (ampicillin) and streptomycin, which showed the lowest activity. For antifungal activity, the oil was active at 0.01 to $0.04 \mathrm{mg} / \mathrm{mL}$ and minimum fungicidal concentration (MFC) of 0.01 to $0.04 \mathrm{mg} / \mathrm{mL}$, whereas the control ketoconazole achieved MIC at 0.15 to $1.5 \mathrm{mg} / \mathrm{mL}$ and $\mathrm{MFC}$ at 0.2 to $2.0 \mathrm{mg} / \mathrm{mL}$, and bifonazole showed $\mathrm{MIC}$ at 0.1 to $0.2 \mathrm{mg} / \mathrm{mL}$ and $\mathrm{MFC}$ at 0.2 to $0.3 \mathrm{mg} / \mathrm{mL}$ (Table 2, Table 3).

Generally, the fungi appear to be more sensitive than the bacteria. Correlation between the achieved antimicrobial activity of selected EO and their chemical composition leads us to infer that the activity may be ascribed to carvacrol, which was present at a high percentage in the oils. Carvacrol has been shown to be a good antimicrobial agent in previous studies (Nostro and Papalia, 2012). Previous reports showed that carvacrol inhibits growth of Aspergillus niger at $50 \mu \mathrm{g} / \mathrm{mL}$, Aspergillus fumigates, Micrococcus flavus, and Aspergillus ochraceus at $100 \mu \mathrm{g} / \mathrm{mL}$, as well as Penicillium chrysogenum at $500 \mu \mathrm{g} / \mathrm{mL}$ (Abbaszadeh et al., 2014). The MIC of carvacrol against 16 Candida albicans strains was $256 \mu \mathrm{g} / \mathrm{mL}$ and MFC was $512 \mu \mathrm{g} /$ mL (Lima et al., 2013). Against 4 Streptococcus strains, carvacrol showed MIC of $2.5 \mathrm{mg} / \mathrm{mL}$ and minimum bacterial concentration of $5 \mathrm{mg} / \mathrm{mL}$, whereas against

\section{BHT (IS)}
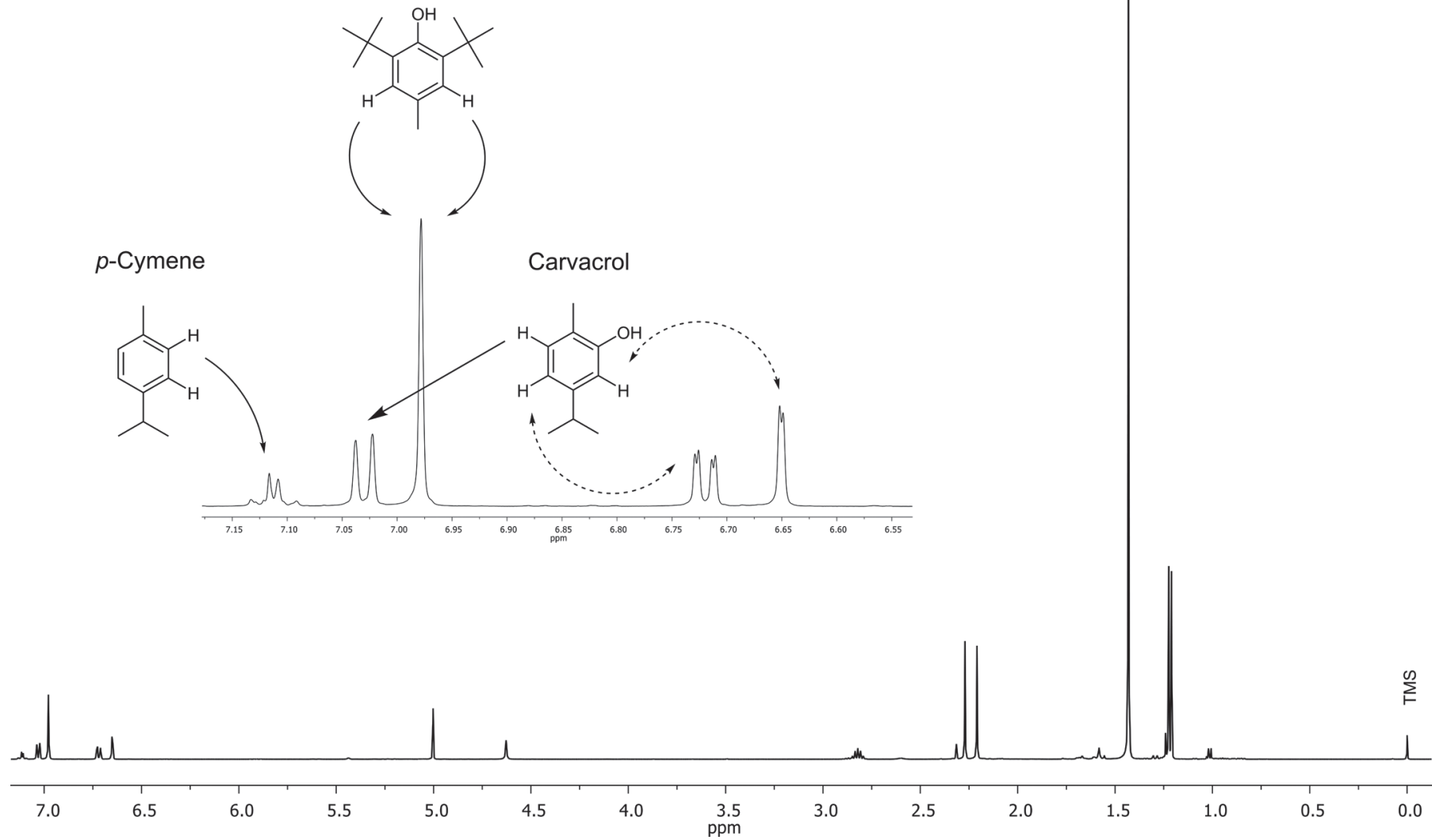

Figure 1. Quantitative ${ }^{1} \mathrm{H}$ nuclear magnetic resonance $(500 \mathrm{MHz}$, deuterated chloroform) analysis of the essential oil of Thymus algeriensis with 2,6-bis(1,1-dimethylethyl)-4-methylphenol (BHT) as an internal standard. Expansion showed signals from aromatic protons of BHT, carvacrol, and $p$-cymene used for quantitative calculations. 
Table 1. Chemical composition of Thymus algeriensis essential oil analyzed by GC-MS and GC-flame-ionization detection ${ }^{1}$

\begin{tabular}{lrlc}
\hline$t_{\mathrm{R}}(\min )$ & $\mathrm{RI}$ & Compound & $\%$ \\
\hline 5.52 & 922 & $\alpha$-Thujene & 0.2 \\
5.69 & 929 & $\alpha$-Pinene & 0.5 \\
6.09 & 943 & Camphene & 0.1 \\
6.88 & 972 & $\beta$-Pinene & $<0.1 \%$ \\
7.26 & 986 & Myrcene & 0.9 \\
7.72 & 1,002 & $\alpha$-Phellandrene & 0.1 \\
7.90 & 1,007 & 3-Carene & 0.1 \\
8.10 & 1,012 & $\alpha$-Terpinene & 0.8 \\
8.39 & 1,020 & p-Cymene & 7.7 \\
8.54 & 1,024 & $\beta$-Phellandrene & 0.5 \\
9.60 & 1,054 & $\gamma$-Terpinene & 3.6 \\
10.76 & 1,086 & Terpinolene & $<0.1 \%$ \\
11.21 & 1,098 & Linalool & 1.1 \\
13.95 & 1,161 & Borneol & 0.5 \\
14.49 & 1,174 & Terpinene-4-ol & 0.6 \\
15.21 & 1,190 & $\alpha$-Terpineol & 0.1 \\
19.61 & 1,290 & Thymol & 0.3 \\
20.23 & 1,300 & Carvacrol & 80.9 \\
25.07 & 1,415 & $\beta$-Caryophyllene & 1.2 \\
26.54 & 1,450 & $\alpha$-Humulene & $<0.1 \%$ \\
31.95 & 1,580 & Caryophyllene oxide & 0.5 \\
& & Total & 99.7 \\
\hline 1 & & & 0.25 \\
\hline
\end{tabular}

${ }^{1} t_{\mathrm{R}}=$ retention time on HP-5MSI capillary column $(30 \mathrm{~m} \times 0.25 \mathrm{~mm}$ i.d., film thickness $0.25 \mu \mathrm{m}$,) RI = retention indices computed by comparison with retention times of $n$-alkanes under the same chromatographic conditions (Vandendool and Kratz, 1963); relative percentage calculated by GC-FID peak areas.
Candida albicans MIC was $1.25 \mathrm{mg} / \mathrm{mL}$ and MFC was $2.5 \mathrm{mg} / \mathrm{mL}$ (Botelho et al., 2007). Ramos et al. (2013) showed that carvacrol is safe for use with food for human consumption.

The results of in situ treatment of sliced cheese with EO of T. algeriensis are given in Table 4 as contamination incidence (\%). For $30 \mathrm{~d}$ after treatment and inoculation with $P$. aurantiogriseum, pieces of sliced cheese were kept at $4^{\circ} \mathrm{C}$. The incidence of contamination decreased with increasing EO concentration, with contamination being completely absent at the highest dose used. Results showed that $100 \%$ of control sliced cheese initially developed infection (Figure 3 ). Contamination incidence of $P$. aurantiogriseum in sliced cheese decreased from 66 to $0.0 \%$ with increasing concentrations of EO from 20 to $25 \mu \mathrm{L} / \mathrm{mL}$, respectively. Lower concentrations of EO had no effect on contamination incidence and it remained at $100 \%$. Higher concentrations of EO needed to prevent cheese contamination and the low contamination incidence, in contrast to the in vitro microdilution method, suggested that cheese is a more complex medium than the laboratory broths used in in vitro antimicrobial assays. In commonly used doses (up to 20 drops per day; as a culinary herb), no acute or chronic toxicity has been reported for thyme

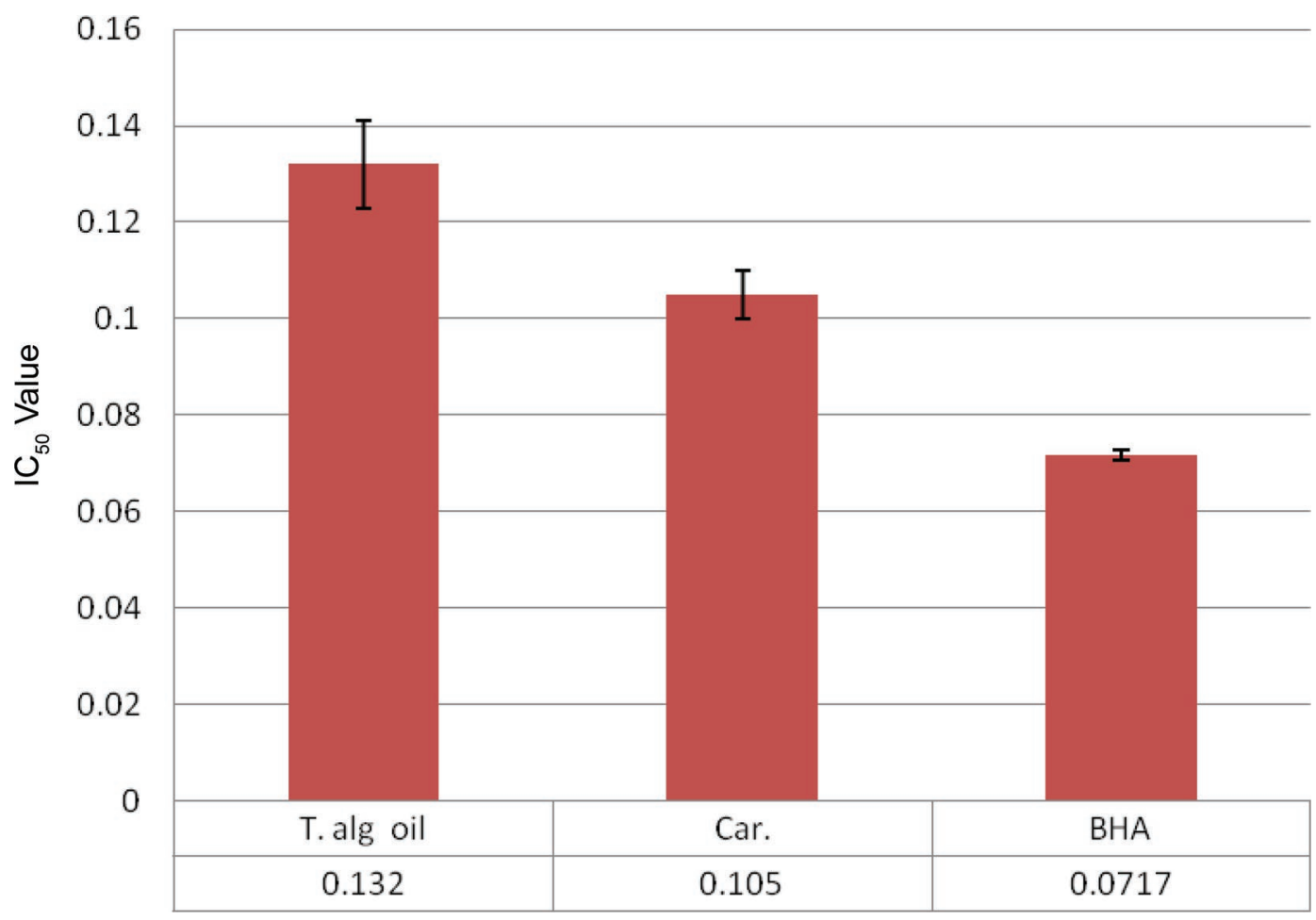

Figure 2. Half-maximal inhibitory concentration $\left(\mathrm{IC}_{50}\right)$ values with standard deviations of essential oil tested in a 1,1-diphenyl-2-picrylhydrazyl assay with its principal compound carvacrol and positive control butylated hydroxyl anisole (BHA). Color version available online. 
SHORT COMMUNICATION: CHEESE WITH THYMUS ALGERIENSIS
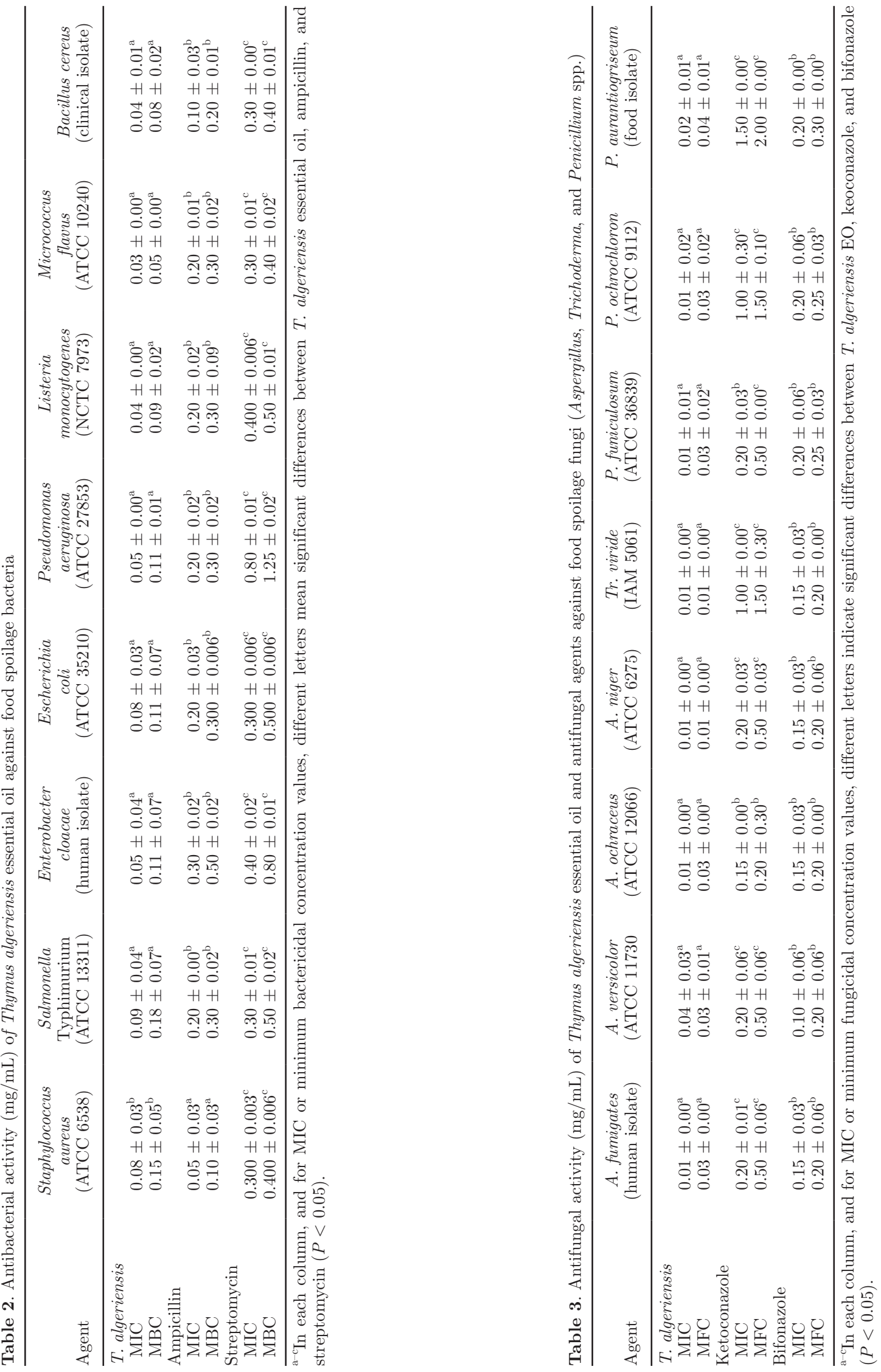


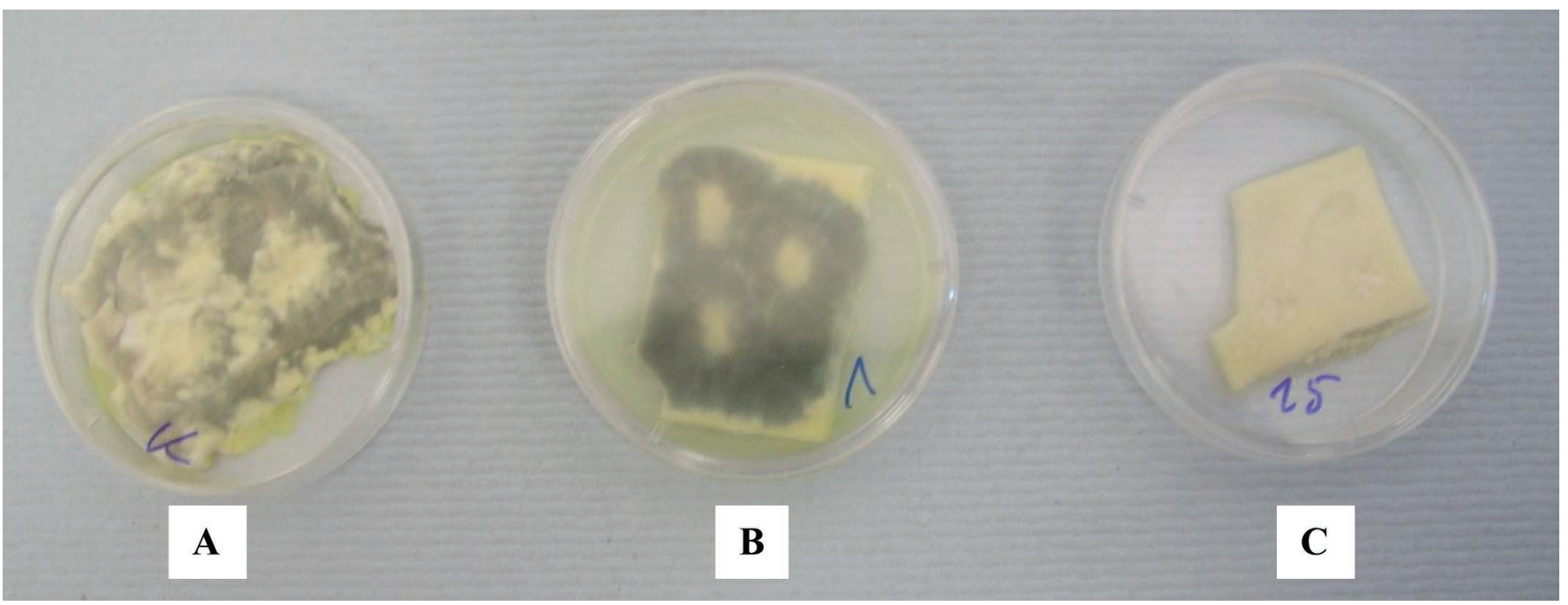

Figure 3. Contamination of sliced cheese with Penicillium aurantiogriseum after $30 \mathrm{~d}$ of storage at $4^{\circ} \mathrm{C}$. (A) Control sample not treated with essential oil of Thymus algeriensis showing fully developed contamination; (B) sample of cheese treated with concentration of $1 \mu \mathrm{L}$ per well in cheese; and (C) sample of cheese treated with the highest concentration of $15 \mu \mathrm{L}$ per well in cheese, showing no contamination. Color version available online.

oil (Mills and Bone, 2000); thus, the applied doses in our study are considered as safe for use.

Results of sensory evaluation of cheese sprayed with EO showed no changes in texture and color on surface of cheese slices after $30 \mathrm{~d}$ of storage at temperature $4^{\circ} \mathrm{C}$ (Table 5). The results indicated increasing grades

Table 4. Incidence of contamination with Penicillium aurantiogriseum of cheese treated with essential oil of Thymus algeriensis (EO)

\begin{tabular}{lc}
\hline EO $(\mu \mathrm{L} /$ well $)$ & Contamination incidence $(\%)$ \\
\hline 0 & 100.0 \\
1 & 100.0 \\
5 & 100.0 \\
10 & 100.0 \\
15 & 100.0 \\
20 & 66.0 \\
\hline
\end{tabular}

Table 5. Changes in color, texture, and taste during storage of $30 \mathrm{~d}$ at $4^{\circ} \mathrm{C}^{1}$ in control cheese slices and samples with different concentrations of essential oils (EO) added

\begin{tabular}{lcccc}
\hline & & \multicolumn{3}{c}{$\begin{array}{c}\text { EO added per well } \\
\text { in cheese }(\mu \mathrm{L})\end{array}$} \\
\cline { 3 - 5 } Item & $\begin{array}{c}\text { Control } \\
(\text { no EO) }\end{array}$ & 1 & 5 & 15 \\
\hline Color & 3.6 & 4.4 & 4.5 & 4.6 \\
Texture & 4.2 & 3.9 & 4.0 & 4.2 \\
Taste & 4.3 & 3.7 & 3.6 & 3.1 \\
\hline
\end{tabular}

${ }^{1}$ The results are expressed as the average of all grades: $1=$ extremely dislike, $2=$ dislike, $3=$ neither like nor dislike, $4=$ like; $5=$ extremely like.

Journal of Dairy Science Vol. 101 No. 5, 2018 of color with addition of EO, whereas cheese taste was decreased but still was above the limits for nonliked products.

Thymus algeriensis EO showed antimicrobial potential against the food pathogenic mold $P$. aurantiogriseum in vitro as well as in real food (cheese) systems. The high amounts of carvacrol present in the oil are likely responsible for the antimicrobial activity. Thymus species are well-known culinary spices widely used all around the world, with pleasant taste and flavor. With high antifungal and antiradical abilities, this EO could be recommended as natural antimicrobial additive for shelf-life prolongation of the soft cheese.

\section{ACKNOWLEDGMENTS}

This research was supported by a grant from the Ministry of Education, Science and Technological Development of Serbia (Projects No. 173029, 173032 and 172053).

\section{REFERENCES}

Abbaszadeh, S., A. Sharifzadeh, H. Shokri, A. R. Khosravi, and A. Abbaszadeh. 2014. Antifungal efficacy of thymol, carvacrol, eugenol and menthol as alternative agents to control the growth of food-relevant fungi. J. Mycol. Med. 24:e51-56.

Adams, R. P. 2007. Identification of Essential Oil Components by Gas Chromatography/Mass Spectrometry. 4th ed. Allured Publ., Carol Stream, IL.

Babaei, M., M. E. Abarghoei, R. Ansari, A. A. Vafaei, A. A. Taherian, M. M. Akhavan, G. Toussy, and S. Mousavi. 2008. Antispasmodic effect of hydroalcoholic extract of Thymus vulgaris on the guinea pig-ileum. Nat. Prod. Res. 22:1143-1150. 
Botelho, M. A., N. A. P. Nogueira, G. M. Bastos, S. G. C. Fonseca, T. L. G. Lemos, F. J. A. Matos, D. Montenegro, J. Heukelbach, V. S. Rao, and G. A. C. Brito. 2007. Antimicrobial activity of the essential oil from Lippia sidoides, carvacrol and thymol against oral pathogens. Braz. J. Med. Biol. Res. 40:349-356.

Bukvicki, D., A. Cirić, M. Soković, L. Vannini, L. Nissen, M. Novaković, Lj. Vujisić, Y. Asakawa, and P. D. Marin. 2016. Micromeria thymifolia essential oil suppresses quorum-sensing signaling in Pseudomonas aeruginosa. Nat. Prod. Commun. 11:1903-1906.

Bukvicki, D., D. Gottardi, A. K. Tyagi, M. Veljic, P. D. Marin, Lj. Vujisic, M. E. Guerzoni, and L. Vannini. 2014b. Scapania nemorea liverwort extracts: Investigation on volatile compounds, in vitro antimicrobial activity and control of Saccharomyces cerevisiae in fruit juice. Lebensm. Wiss. Technol. 55:452-458.

Bukvicki, D., D. Stojkovic, M. Sokovic, M. Nikolic, L. Vannini, C. Montanari, and P. D. Marin. 2015. Potential application of Micromeria dalmatica essential oil as a protective agent in a food system. Lebensm. Wiss. Technol. 63:262-267.

Bukvicki, D., D. Stojkovic, M. Sokovic, L. Vannini, C. Montanari, B. Pejin, A. Savic, M. Veljic, S. Grujic, and P. D. Marin. 2014a. Satureja horvatii essential oil: In vitro antimicrobial and antiradical properties and in situ control of Listeria monocytogenes in pork meat. Meat Sci. 96:1355-1360.

Dzamić, A., B. Nikolic, A. Giweli, D. Mitic-Culafic, M. Sokovic, M. Ristic, J. Knezevic-Vukcevic, and P. Marin. 2015. Libyan Thymus capitatus essential oil: Antioxidant, antimicrobial, cytotoxic and colon pathogen adhesion-inhibition properties. J. Appl. Microbiol. 119:389-399.

Fachini-Queiroz, F.C., R. Kummer, C.F. Estevao-Silva, M.D. Carvalho, J. M. Cunha, R. Grespan, C. A Bersani-Amado, and R. K. Nakamura Cuman. 2012. Effects of thymol and carvacrol, constituents of Thymus vulgaris L. essential oil, on the inflammatory response. Evid. Based Complement. Altern. Med. 2012:657026. https://doi.org/10.1155/2012/657026.

Gammariello, D., A. Conte, and M. A. Del Nobile. 2010. Assessment of chitosan and extracts of lemon and sage as natural antimicrobial agents during Fior di latte cheese-making. Int. J. Dairy Technol. 63:530-537.

Gottardi, D., D. Bukvicki, S. Prasad, and A. K. Tyagi. 2016. Beneficial effects of spices in food preservation and safety. Front. Microbiol. $7: 1394$.

Hazzit, M., A. Baaliouamer, A. R. Verissimo, M. L. Faleiro, and M. G. Miguel. 2009. Chemical composition and biological activities of Algerian Thymus oils. Food Chem. 116:714-721.

Lee, S. J., K. Umano, T. Shibamoto, and K. G. Lee. 2005. Identification of volatile components in basil (Ocimum basilicum L.) and thyme leaves (Thymus vulgaris L.) and their antioxidant properties. Food Chem. 91:131.
Lima, I. O., F. O. de Oliveira Pereira, W. A. de Oliveira, E. de Oliveira Lima, E. A. Menezes, F. A. Cunha, and M. F. F. M. Diniz. 2013. Antifungal activity and mode of action of carvacrol against Candida albicans strains. J. Essent. Oil Res. 25:138-142. https://doi .org/10.1080/10412905.2012.754728.

Lucera, A., C. Costa, A. Conte, and M. A. Del Nobile. 2012. Food applications of natural antimicrobial compounds. Front. Microbiol. $3: 287$.

McLafferty, F. W. 2005. Wiley Registry of Mass Spectral Data: With NIST 2005 Spectral Data, 7th rev. ed., John Wiley and Sons Ltd., New York, NY.

Mills, S., and K. Bone. 2000. Principles and Practice of Phytotherapy. Churchill Livingstone, Toronto, Canada.

NIST. 2011. NIST/NIH/EPA Mass Spectral Library, Standard Reference Database 1, NIST 11. Standard Reference Data Program, National Institute of Standards and Technology, Gaithersburg, MD.

Nostro, A., and T. Papalia. 2012. Antimicrobial activity of carvacrol: current progress and future prospectives. Recent Pat. Antiinfect. Drug Discov. 7:28-35.

Oussalah, M., S. Caille, L. Saucier, and M. Lacroix. 2007. Inhibitory effects of selected plant essential oils on the growth of four pathogenic bacteria: E. coli O157:H7, Salmonella typhimurium, Staphylococcus aureus and Listeria monocytogenes. Food Control 18:414-420.

Ramos, M., A. Beltran, A. Valdes, M. A. Peltzer, A. Jimenez, M. A. Peltzer, A. Jimenez, M. C. Garrigos, and G. E. Zaikov. 2013. Carvacrol and Thymol for Fresh Food Packaging. J. Bioequiv. 5:154-160. https://doi.org/10.4172/jbb.1000151.

Rios, J. L., M. C. Recio, and A. Villar. 1988. Screening methods for natural antimicrobial products with antimicrobial activity: A review of the literature. J. Ethnopharmacol. 23:127-149.

Skrinjar, M., and N. Nemet. 2009. Antimicrobial effects of spices and herbs essential oils. Acta Period. Technol. 40:195-209.

Smith-Palmer, A., J. Stewart, and L. Fyfe. 2001. The potential application of plant essential oils as natural food preservatives in soft cheese. Food Microbiol. 18:463-470.

Torkar, K. G., and A. Vengust. 2008. The presence of yeasts, moulds and aflatoxin M1 in raw milk and cheese in Slovenia. Food Control 19:570-577.

Tyagi, A. K., D. Bukvicki, D. Gottardi, G. Tabanelli, C. Montanari, A Malik, and M. E. Guerzoni. 2014. Eucalyptus essential oil as a natural food preservative: In vivo and in vitro antiyeast potential. BioMed Res. Int. 2014:969143. https://doi.org/10.1155/2014/ 969143.

Vandendool, H., and P. D. Kratz. 1963. A generalization of the retention index system including linear temperature programmed gas-liquid partition chromatography. J. Chromatogr. 11:463-471. 